\title{
Article
}

\section{The Impact of New Urbanization Policy on In Situ Urbanization-Policy Test Based on Difference-in- Differences Model}

\author{
Jing Peng ${ }^{1}\left(\mathbb{D}\right.$, Yanhong Liu ${ }^{1,2, *}$, Qi Wang ${ }^{3}$, Guoping Tu ${ }^{1}(\mathbb{D})$ and Xinjian Huang ${ }^{1,4}$ \\ 1 School of Management, Nanchang University, Nanchang 330031, China; pjsophie@email.ncu.edu.cn (J.P.); \\ tgping@ncu.edu.cn (G.T.); xjhuang@ncu.edu.cn (X.H.) \\ 2 Department of City and Regional Planning, The University of North Carolina at Chapel Hill, \\ Chapel Hill, NC 27514, USA \\ 3 School of Information Engineering, Nanchang University, Nanchang 330031, China; \\ qiwang@email.ncu.edu.cn \\ 4 Financial College, Jiangxi Normal University, Nanchang 330022, China \\ * Correspondence: yanhong_liu@email.ncu.edu.cn; Tel.: +86-130-0620-0216
}

Citation: Peng, J.; Liu, Y.; Wang, Q.; Tu, G.; Huang, X. The Impact of New Urbanization Policy on In Situ Urbanization-Policy Test Based on Difference-in-Differences Model.

Land 2021, 10, 178. https://doi.org/ 10.3390/land 10020178

Academic Editor: Thomas Maloutas

Received: 4 January 2021

Accepted: 8 February 2021

Published: 9 February 2021

Publisher's Note: MDPI stays neutral with regard to jurisdictional claims in published maps and institutional affiliations.

Copyright: (c) 2021 by the authors. Licensee MDPI, Basel, Switzerland. This article is an open access article distributed under the terms and conditions of the Creative Commons Attribution (CC BY) license (https:// creativecommons.org/licenses/by/ $4.0 /)$.

\begin{abstract}
Compared with traditional urbanization, new urbanization is more closely aligned with China's basic national conditions and reflects the basic goal of sustainable development. As the main method of new urbanization, in situ urbanization can make up for the shortcomings of traditional urbanization. The establishment of national new urbanization pilot areas is an important element of the new urbanization policy. This paper tests the policy effect of the National New-type Urbanization Plan (2014-2020) on in situ urban development through the establishment of pilot areas. We found the following: (1) In the central region, the establishment of new urbanization pilot areas has not played a significant role in promoting the process of in situ urbanization. By dividing the central cities into Yangtze River and non-Yangtze River Economic Belt areas, we also find that the effect of the new urbanization policy is not obvious, for these cities are not located in the Yangtze River Economic Belt. (2) The central cities located in the Yangtze River Economic Belt have seen significant policy effects due to their advantages in transportation, resources, industry, labor, etc. The establishment of new urbanization pilot areas has a significant promoting effect on the process of in situ urbanization.
\end{abstract}

Keywords: new urbanization policy; in situ urbanization; difference-in-differences; policy test

\section{Introduction}

Urbanization is a natural and historical process of non-agricultural industries gathering in urban areas along with the development of industrialization. It is an objective trend of human societal development and an important symbol of national modernization [1]. At present, China is in the late stage of industrialization and accelerated development of urbanization. However, as China is still in the social transformation period, its urban public resources, services, and other supporting facilities are not perfect and do not match the speed of urbanization [2]. This reduces the quality of citizens' lives and makes "urban disease" and other problems more serious. According to the National New-type Urbanization Plan (2014-2020), the urbanization rate of permanent residents in China should have reached $60 \%$ by 2020 , with the urban population exceeding 800 million. About 100 million rural and other migrant people were expected to be settled in cities and towns [3]. In fact, our cities' resources, energy, and environmental carrying capacity cannot accommodate the large population [4]. Since the reform and opening up, the rural economy has developed by leaps and bounds, and the level of agricultural modernization and mechanization has been greatly improved, which provides a powerful economic and spatial condition for rural urbanization [5]. In this case, it becomes the inevitable choice of new urbanization 
to change the original mode and implement the in situ urbanization mode, which makes farmers work in native lands $[6,7]$.

Compared with traditional urbanization, new urbanization is more aligned with China's basic national conditions and reflects the basic goal of sustainable development [8]. In situ urbanization is the main way that new urbanization can make up for the shortcomings of traditional urbanization [9]. First, it makes up for the ecological defects. New urbanization focuses on creating a livable environment in harmony between humans and nature [10], which is fundamentally different from traditional urban forms. The development of in situ urbanization can help overcome the ecological defects of traditional cities and lay a foundation for building a beautiful China. Second, it can improve the relationship between urban and rural areas. In the context of balanced urban and rural development, the traditional urbanization model is not conducive to narrowing the gap between urban and rural areas but will widen the gap, forming an urban-rural dichotomy [11]. On the premise of activating rural resources and improving farmers' quality of life, new urbanization plays a positive role in improving urban-rural relations [9]. Third, it helps in alleviating urban diseases, such as traffic congestion and serious environmental pollution. With the continuous speeding up of urban development, such urban diseases bring great troubles to people living in cities and seriously affect sustainable development [12,13].

It is obviously unscientific to pay one-sided attention to the expansion of urban scale and economic development. The excessive agglomeration of large cities will gradually increase the pressure of cities. In order to alleviate the urban pressure, local governments should optimize urban system from the perspective of balancing urban and rural development [14]. In situ urbanization is conducive to the development of small towns and has a certain effect on relieving the pressure of large cities [15].

Next, this paper evaluates the impact of the National New-type Urbanization Plan (2014-2020) on the in situ urbanization process in China. Specifically, our objectives were to (1) quantify the in situ urbanization rate of 87 prefecture-level cities in the central region; (2) test the policy effect of the plan on the in situ urbanization process by using the difference-in-differences (DID) model; and (3) put forward appropriate policy suggestions to effectively promote in situ urbanization.

The structure of the remaining sections is as follows: Section 2 is a literature review; Section 3 presents the model and descriptions of variables; Section 4 provides an analysis of in situ urbanization; Section 5 outlines the empirical test; and Section 6 gives the conclusions, limitations, and implications.

\section{Literature Review}

At present, there are relatively few studies on in situ urbanization. The concept of in situ urbanization in China was first proposed by Zhu [16], who defined it as the transformation of a large number of rural populations to towns without a large-scale spatial transfer. Since then, scholars have conduct supplementary studies on the definition of in situ urbanization from the perspectives of spatial scope and conceptual connotations [17-21]. From the perspective of spatial scope, "in situ" is mainly relative to long-distance urbanization, but there are different opinions on the size of "in situ" scope at present. Some scholars believe that when the rural economy develops to a certain extent, the process of in situ urbanization takes rural areas where farmers live as the core, and changes the original natural way of life in rural areas by improving infrastructure construction, so that farmers will no longer move blindly to other places [22]. Some authors thought that if the county is taken as the smallest regional unit of spatial transfer, large populations congregating in towns at the county scale can be regarded as a generalized process of in situ urbanization [23]. In addition, some authors distinguished between in situ and nearby urbanization, believing that the former refers to the close migration of rural residents to towns near their homes, while the latter is centered on prefecture-level cities and county-level towns [24].

Currently, the research on in situ urbanization mainly focuses on three aspects: the mode, influencing factors, and development path. Regarding the research on the mode, 
Qian [25] proposed three modes of urbanization from the perspective of spatial scope. The first and second are to implement in situ urbanization of the agricultural population by developing a county economy and promoting the rise of strong towns, and the third is to promote urban-rural integration and in situ urbanization of the whole region with countylevel cities as the center. At the same time, as an important model of new urbanization [26], an in-depth exploration of the influencing factors of in situ urbanization can better promote the construction of new urbanization.

As the main aspect of in situ urbanization, rural residents' attributes have an important effect. Young and middle-aged farmers, rural residents with a junior or senior high school education, and married rural residents have a strong desire for local urbanization [27,28]. For the agricultural transfer population, in addition to its own characteristics, external factors such as an urban social network, basic public services, urban price level, and improved living conditions also have a significant impact on the willingness for in situ urbanization $[29,30]$. In addition, the willingness of the migrant agricultural population to urbanize locally also shows regional differences, and is stronger in the central and western regions [31,32]. Although local urbanization has positive effects, such as increasing farmers' incomes and reducing the cost of citizenship, it still faces many difficulties. Therefore, many scholars have put forward development paths and promotion strategies for promoting in situ urbanization further. Zhu (2017) pointed out some problems in China's urbanization and analyzed the relationship between in situ and new urbanization [21]. He believed that the former was the realistic choice for new urbanization at present. Pan et al. (2016). used a DEA model to study the sustainable development of in situ urbanization in Youyang Autonomous County and provided a development path for it [33]. Drawing from ongoing trends and policy potential taken from the New Urbanization Plan (NUP), Xu quantitatively evaluated the level of sustainability of the process in 20 Chinese urban agglomerations and provided some positive suggestions achieving sustainable new urbanization [34].

Although both the government and scholars are aware of the role of in situ urbanization in promoting sustainable urbanization, scholars' attention has not changed from the traditional perspective. They still have evaluated only the implementation and effectiveness of NUP [35-38] and believe that it presents an opportunity for a new roadmap for the orderly conversion of rural migrants into urban residents and optimizing the patterns of urbanization. Other scholars have differentiated and analyzed the impact of the new policy since the launch of the NUP in 2014. However, what is the driving mechanism of in situ urbanization? Compared with other urbanization patterns, what role does the new urbanization policy play in in situ urbanization? What is the reference significance of enacting effective policy for other regions?

The key to answer these questions lies in determining the impact of the new policy on in situ urbanization that has not been addressed. Moreover, by combining the above studies related to local urbanization, it can be found that most of the research still explores the mode, influencing factors, and development path of local urbanization qualitatively, with little research using quantitative or empirical tests. In this paper, we selected the central region as the study area, calculated the in situ urbanization rate of 87 prefecture-level cities based on the connotation of in situ urbanization and then tested the policy effect of the New Urbanization Plan on the process by using the difference-in-differences (DID) model. Our research has two theoretical contributions: First, the in situ urbanization rate is calculated in the form of non-agricultural employment. Second, an empirical model is used to analyze the effect of the in situ urbanization policy.

\section{Methodology}

\subsection{Model}

National New Urbanization Pilot Areas represent an important implementation of the National New-type Urbanization Plan (2014-2020). In order to test the effect of the plan in central China, this paper compares the difference between the in situ urbanization level before and after the pilot areas are established to explore the impact of the new policy. At 
the same time, we consider that before and after the pilot area is established, there are many other factors that will affect the level of in situ urbanization. In addition, other policies issued during the same period may also be beneficial to cities that have not established pilot areas. These factors will undoubtedly have an important impact on the process of in situ urbanization and affect the results of policy evaluation. Therefore, this paper draws on the idea of difference-in-differences [39] and designs a quasi-natural experiment, taking prefecture-level cities (autonomous prefectures) where the policy is implemented as the experimental group and cities that where the policy has not been implemented as the control group. Then, by calculating the double difference in the two groups between before and after the pilot area was established, the net impact of the pilot area on the development of in situ urbanization can be effectively tested.

Among the 87 prefecture-level cities (autonomous prefectures) in central China studied in this paper, as of 2018, 52 of them were approved as national new urbanization pilot areas. This provides a good quasi-natural experiment for research. The difference-in-differences method is applicable. Specifically, in the sample of this study, 52 prefecture-level cities were approved as national new urbanization pilot areas, and these constitute the treatment group, while the remaining 35 prefecture-level cities that were not approved naturally constitute the control group. At the same time, the State Council approved new urbanization pilot areas by stages: 40 prefecture-level cities including Anhui Province, Wuhan, and Changsha in 2015 and 12 prefecture-level cities including Xiangtan, Pingxiang, and Ganzhou in 2016. Taking into account the time difference in establishing pilot areas in various regions, this paper constructs the following time-varying difference-in-differences (DID) model to test the net effect of new urbanization pilot areas on in situ urbanization. The model is set as follows:

$$
y_{i, t}=\alpha+\mu_{i}+\lambda_{t}+\theta D I D_{i, t}+\beta X_{i, t}+\varepsilon_{i, t}
$$

where $y_{i, t}$ is the explained variable, $i(i=1, \ldots, N)$ represents an individual, $t(t=1, \ldots, T)$ represents time; DID is the core explanatory variable, denoted by treat $_{i} \times$ post $_{i, t}$; and treat $_{i}$ is the dummy variable of the treatment group. If individual $i$ belongs to the treatment group impacted by the policy, the treat $t_{i}$ value is 1 or 0 . post $t_{i, t}$ is the dummy variable of the treatment period. The individual will be impacted by the policy in the treatment period (and was not impacted before). If individual $i$ enters the treatment period, the post $t_{i, t}$ value is 1 ; otherwise, it is 0 . The coefficient of interaction term $\theta$ is the treatment effect of concern in this study, if $\theta>0$, we believe that the establishment of new urbanization pilot areas can promote the process of in situ urbanization. $\mu_{i}$ is the individual fixed effect, $\lambda_{t}$ is the time fixed effect, $X_{i, t}$ represents the control variables that change with time and individuals, $\beta$ is the coefficient of the control variable, and $\varepsilon_{i, t}$ is the error term.

\subsection{Variable Descriptions}

This paper focuses on the role of new urbanization pilot areas in in situ urbanization and analyzes the regional differences of the pilot areas. In addition, considering that other factors will also affect in situ urbanization, we introduce some control variables.

In our research, the explained variable is the in situ urbanization level, which is represented by the in situ urbanization rate. The in situ urbanization rate is calculated according to Equation (1) in Section 3. The core explanatory variable is the policy dummy variable $(D I D)$. New urbanization pilot areas are not established at the same time but are scattered at different times. According to the time that pilot areas are established, we set all the years before establishment as $0(D I D=0)$ and all the years after establishment as 1 $(D I D=1)$. In 2015 and 2016, 40 and 12 prefecture-level cities in central China, respectively, were approved as new urbanization pilot areas, for a total of 52 cities. These constituted the experimental group, while the remaining 35 unapproved prefecture-level cities constituted the control group.

The control variables we selected were as follows: (1) Urban-rural income gap (GAP). This paper used the ratio of per capita disposable income of urban residents and per capita net income of rural residents to represent the urban-rural income gap. In order to eliminate 
the impact of price factors, we adjusted these two based on the consumer price indices in the prefecture-level cities from 2009 to 2018. The estimated coefficient of this variable is expected to be negative. (2) Educational resources $(E D U)$. The allocation system of public educational resources has further intensified the polarization of population and economic resources in central China [40]. The flow of human resources caused by the allocation of educational resources has further emptied necessary intellectual capital in less developed regions of central China, which is not conducive to in situ urbanization in those regions. We chose the number of full-time college teachers as the proxy variable of educational resources $(E D U)$, and the estimated coefficient of this variable is expected to be negative. (3) Government support (GOV). This paper uses government fiscal expenditure in the agriculture sector to represent support for rural economic development. We hold the view that the more government support in rural areas there is, the more beneficial it will be for rural residents to obtain local employment, which plays a role in promoting in situ urbanization. The estimated coefficient of this variable is expected to be positive. (4) Traffic accessibility (TRA). Traffic accessibility will greatly accelerate the movement of the population between urban and rural areas. The developed and convenient traffic conditions between urban and rural areas will strongly attract the migration of residents in rural areas. From the perspective of in situ urbanization, this is conducive to the flow of rural residents to urban areas but not to the process of in situ urbanization to some extent. We use the urban road area ratio (the ratio of total urban road acreage to total acreage of the city) to represent traffic convenience (TRA). (5) Medical level (MED). A higher medical level in cities strongly attracts rural residents to move, which is not conducive to the in situ transfer of rural labor. In this paper, the average number of medical practitioners per thousand residents in each prefecture-level city is used to represent the medical level $(M E D)$. Considering the possible fluctuations and heteroscedasticity in the samples, we treated all variables logarithmically. All the data of explanatory variables and control variables were collected from the Statistical Yearbook of Chinese Cities and the statistical yearbooks of the six provinces. Descriptive statistics of the above variables are shown in Table 1.

Table 1. Descriptive statistics. IU, in situ urbanization; GAP, urban-rural income gap; EDU, educational resources; GOV, government support; TRA, traffic accessibility; MED, medical level.

\begin{tabular}{ccccccccc}
\hline \multirow{2}{*}{ Variables } & \multicolumn{3}{c}{ Experimental Group } & \multicolumn{4}{c}{ Control Group } \\
\cline { 2 - 9 } & Mean & SE & Max & Min & Mean & SE & Max & Min \\
\hline IU & 0.5126 & 0.0866 & 0.7755 & 0.3004 & 0.4637 & 0.0973 & 0.7155 & 0.2795 \\
GAP & 0.4171 & 0.0723 & 0.5906 & 0.2483 & 0.3988 & 0.0809 & 0.6237 & 0.2239 \\
EDU & 7.7850 & 1.2499 & 10.9731 & 5.2933 & 7.0634 & 1.5912 & 9.3271 & 0 \\
GOV & 0.1712 & 0.0629 & 0.4235 & 0.0461 & 0.1084 & 0.0758 & 0.0714 & 0.5016 \\
TRA & 5.6374 & 0.7173 & 6.8942 & 3.6378 & 5.5309 & 0.9726 & 7.2928 & 1.9459 \\
MED & 10.3697 & 0.5570 & 11.7845 & 8.7759 & 10.2190 & 0.5153 & 11.3913 & 8.7828 \\
\hline
\end{tabular}

\subsection{Steps}

The steps of the empirical analysis are shown as a flowchart in Scheme 1. 


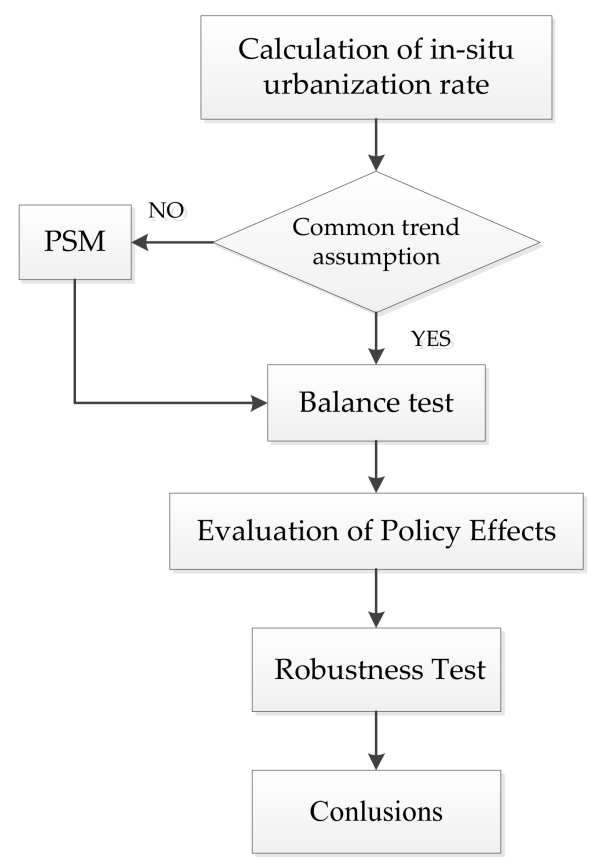

Scheme 1. Steps of empirical analysis.

Step 1. Calculate the in situ urbanization level based on the principle of non-agricultural employment.

Step 2. Test the common trend hypothesis. If the hypothesis holds, then do the balance test. If not, introduce propensity score matching (PSM) to solve the problem that samples cannot meet the common trend and randomness.

Step 3. Use the nearest neighbor matching method to carry out a balance test on the covariant.

Step 4. Use DID method to test the policy effect.

Step 5. Adopt counterfactual test and single difference test to strengthen the robustness of results.

\section{Analysis of In Situ Urbanization Level}

\subsection{Calculation of In Situ Urbanization Rate in Central China}

The central region includes six provinces, Hubei, Hunan, Henan, Anhui, Jiangxi, and Shanxi, covering a land area of 1.03 million $\mathrm{km}^{2}$ [41]. It is the main area with a large population, high density, and low economic development, undertaking the rise of central China [42]. The central regions rely on $10.7 \%$ of the country's land to support $26.51 \%$ of the population and create about $21.69 \%$ of the gross domestic product (GDP) [43]. In 2019, the urbanization rate of the six central provinces was $57.37 \%$, still lower than the national average of $60.60 \%$ [44]. Also, there are still some problems in the central regions, such as unbalanced development between urban and rural areas, large income gap between urban and rural residents, and insufficient industrial promotion in small and medium-sized cities [42]. We selected 87 prefecture-level cities in central China as the research areas.

Currently, there are few studies on the calculation of the in situ urbanization rate. Most of them still focus on the qualitative analysis of in situ urbanization. This study calculates the in situ urbanization rate based on the connotation of in situ urbanization. First, the group emphasized by in situ urbanization is the rural population. Non-agricultural employment is the core connotation of in situ urbanization. Accordingly, we introduced rural employees into the calculation. The calculation formula for the in situ urbanization rate is as follows:

$$
I U=\frac{R N E P}{R E P}
$$


where $I U$ is the in situ urbanization rate, $R N E P$ is the population of rural non-agricultural employment, and REP is the total population of rural employment.

Through Equation (1), this paper calculates the in situ urbanization rate of 87 prefecturelevel cities (autonomous prefectures) in central China from 2009 to 2018. Due to the large number of cities in the six central provinces, we first compared the rates of capital cities in the six central provinces (as shown in Figure 1).

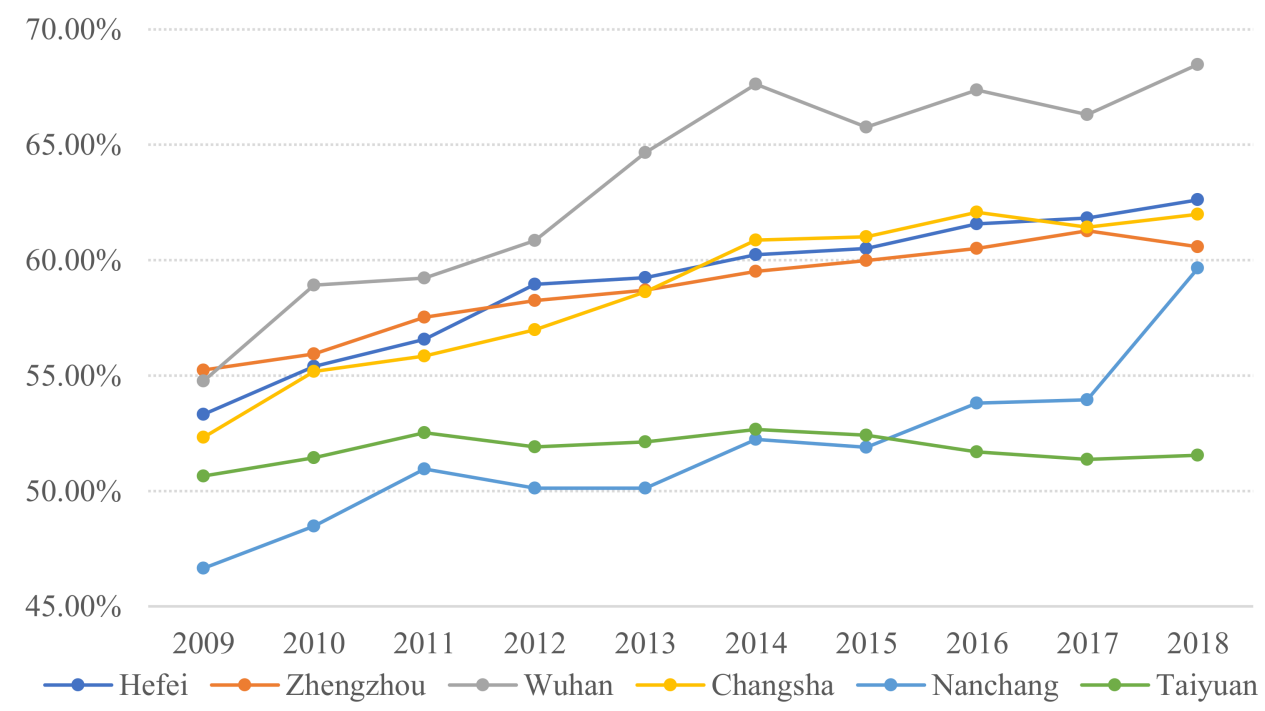

Figure 1. Comparison of in situ urbanization rates among capital cities in six provinces.

From the horizontal comparison of the in situ urbanization rates in capital cities, the rate in Wuhan was slightly lower than that in Zhengzhou in 2009 (54.76\% and 55.24\%, respectively). Since 2009, Wuhan has been in the leading position among the six capital cities, and its in situ urbanization rate is significantly higher than any other capital city in central China. The rates of Zhengzhou, Hefei, and Changsha are relatively close in each period. Figure 1 shows that the three curves interlace each other and maintain stable growth without a big gap. In addition, the in situ urbanization rate of Taiyuan is at a low level among the six capital cities. We can see that the development of in situ urbanization is slow without an obvious improvement in Taiyuan, and the gap between other capital cities is gradually widening. Also, Nanchang's rate was the last among the six capital cities in the early stage, but it developed rapidly and kept narrowing the gap with the other cities. In particular, during 2009-2011 and 2017-2018, there was a substantial increase in the rate of in situ urbanization in Nanchang (4.3\% and 5.7\%, respectively). By 2018, the ranking of the six capital cities in the central region was: Wuhan $(68.49 \%)>$ Hefei $(62.61 \%)$ $>$ Changsha $(62.00 \%)>$ Zhengzhou $(60.59 \%)>$ Nanchang $(59.65 \%)>$ Taiyuan $(51.55 \%)$.

\subsection{Spatial Pattern of Local Urbanization in Central China}

In order to show the spatial changes of in situ urbanization in the central regions intuitively, we used ArcGIS software to visually display the changes in 87 prefecture-level cities (Figure 2). In Figure 2, the in situ urbanization rate is divided into five levels: low (less than 44.86\%), medium-low (44.86-51.19\%), medium (51.19-58.12\%), medium-high (58.12-68.75\%), and high (greater than 68.75\%). The basis for classification is as follows: We used the natural break method of ArcGIS to divide the in situ urbanization rate from high to low into five levels each year, then we obtained the new classification interval by weighing the critical value of the five levels each year. Finally, we adopted the manual method to divide the rate into five grades based on the new classification interval. 


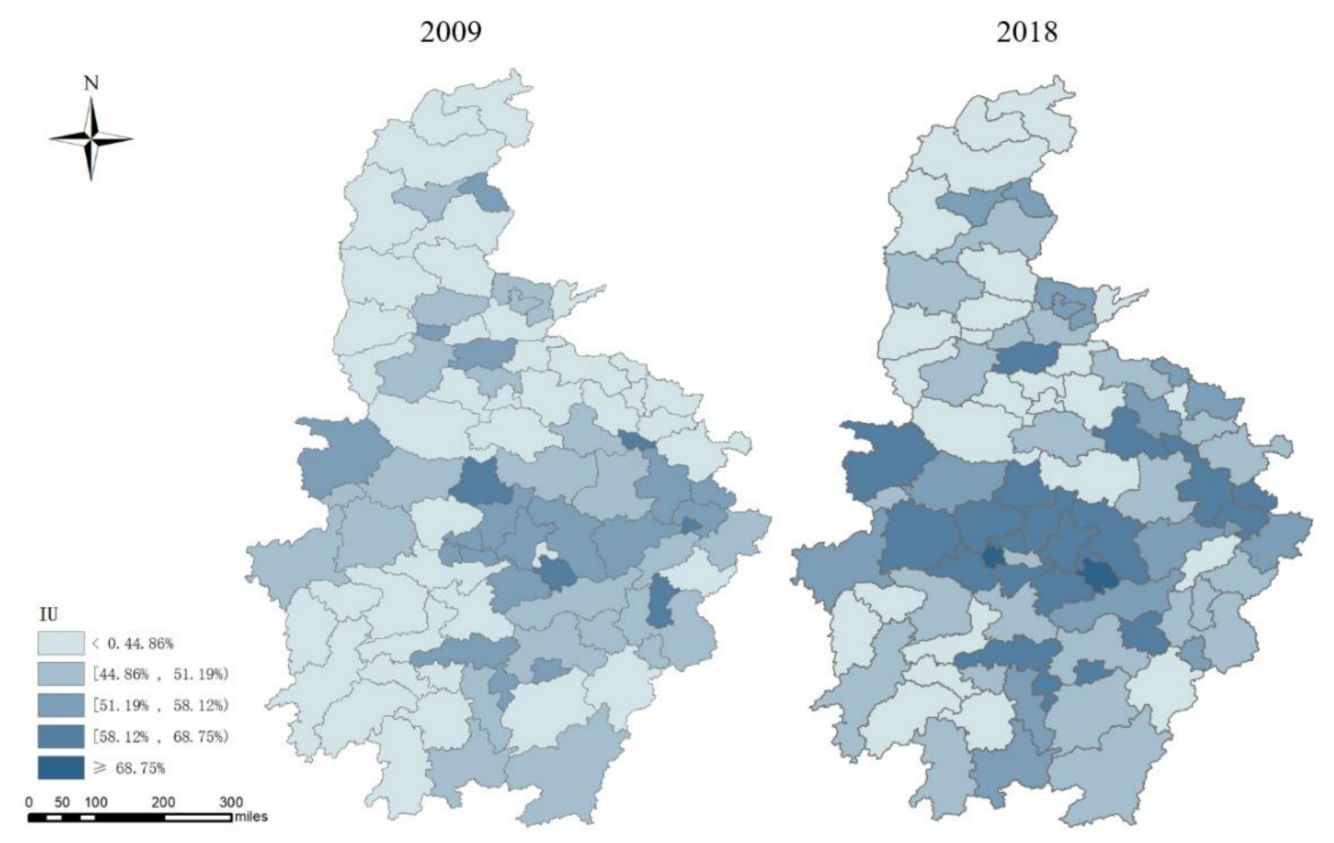

Figure 2. Spatial distribution of in situ urbanization rate in central China.

It can be seen that the in situ urbanization rate of most cities in central China was at a low or medium-low level in 2009 , especially in the surrounding areas with less traffic accessibility. Among these cities, 41 were at the low level and 23 were at the medium-low level. The five cities at the middle-high level (Huangshi, Suizhou, Jingdezhen, Tongling, and Huainan) are distributed in a dotted pattern. Most cities at the middle level of urbanization are adjacent to the middle-high areas, which indicates that regions at the middle-high level played a specific leading role in the surrounding areas during this period. However, cities at the middle-high level have not yet fully developed, so no city in the central region has reached a high level of in situ urbanization.

By comparison, the situation of in situ urbanization in the central region improved overall in 2018, and the number of cities at the low level reduced significantly (41 cities in 2009, 26 cities in 2018). The number of cities at the middle-low level remained the same as in 2009 (23 cities), and the number at the middle-high level increased significantly (5 cities in 2009, 21 cities in 2018). At the same time, two cities with a high level of in situ urbanization emerged. The areas at the middle-high level are no longer star-shaped but show a continuous strip-shaped distribution, which form a circular urbanization structure with Wuhan, Changsha, Nanchang, Hefei, and Zhengzhou as the core cities. Moreover, the outer circle is expanding, showing apparent hierarchical and diffusive effects on the spatial structure of in situ urbanization. Specifically, the diffusion effect of Hubei Province is the most obvious, forming many cities centered on Wuhan at the middle-high level. Among these cities, Jingmen and Ezhou crossed from the low level in 2009 directly to the middle-high level in 2018. In contrast, there some cities were still at a low level of in situ urbanization in northern Shanxi and southwestern Hunan Province in 2018 (6 and 7 cities, respectively). Generally, problems such as poor public services, inconvenient transportation, and insufficient impetus for economic development exist in these cities.

\section{Empirical Test}

\subsection{Influence of New Urbanization Pilot Areas on In Situ Urbanization}

The prerequisite for the difference-in-differences method to be effective is to establish the common trend assumption. If the hypothesis of common trends holds, the impact of new urbanization pilot areas on in situ urbanization will only occur after the pilot area is established; before that, there is no significant difference in the change trend of in situ urbanization level between treatment and control groups. In order to test the common 
trend hypothesis, we used Stata 15.0 software to draw a diagram. The common trend of in situ urbanization level is shown in Figure 3.

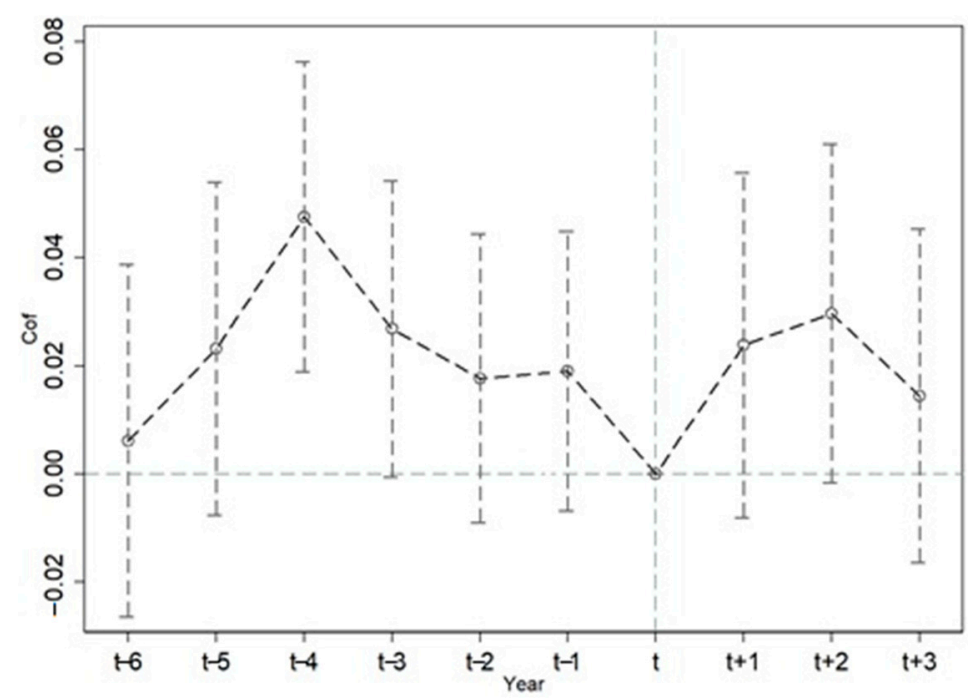

Figure 3. Common trend of in situ urbanization level.

It can be seen from Figure 3 that after the policy is implemented (after period $t$ ), there is a significant difference in the changes of in situ urbanization level between treatment and control groups. However, before the policy is implemented (before period $t$ ), there is a significant difference between the coefficient and 0 . This indicates that there was a significant difference in the change of level between treatment and control groups. The common trend hypothesis does not hold. Therefore, we introduced propensity score matching (PSM) [45] to solve the problem that samples cannot meet the common trend and randomness.

First, we set the variables that have an impact on the in situ urbanization level as covariant, and we selected the control variables as the matching covariant. In this section, the nearest neighbor matching method is adopted to conduct a balance test on the covariant, and the test results are shown in Table 2. According to the test results, the standardized deviation of the single covariant is less than $10 \%$ after matching, which indicates that the single covariate has better balance after matching. The results of the $t$-test also show that the hypothesis that there would be no systematic difference between treatment and control groups could not be rejected. This further proves that there was no systematic difference between treatment and control groups after matching. Table 3 shows the test of overall balance. From the test results in Table 3, we find that the mean value of the standardized deviation was significantly reduced after matching.

For the remaining 783 samples after matching, we performed regression on the matched samples to obtain the results in columns 1 and 2 of Table 4 , showing the estimated results without and with adding control variables, respectively. It can be found that whether control variables are added, the estimated coefficient of DID is positive but not significant, which indicates that for the central region, establishing new urbanization pilot areas does not significantly promote the in situ urbanization process. We guessed that this might be caused by the heterogeneity among different regions, so we divided the 87 prefecture-level cities into the Yangtze River and Non-Yangtze River Economic Belt areas. The Yangtze River area includes four provinces (Hunan, Hubei, Jiangxi, and Anhui), and the non-Yangtze River area includes two provinces (Shanxi and Henan). 
Table 2. Balance test of covariant.

\begin{tabular}{|c|c|c|c|c|c|c|}
\hline \multirow{2}{*}{ Covariant } & \multirow{2}{*}{ Status } & \multicolumn{2}{|c|}{ Mean } & \multirow{2}{*}{ SD (\%) } & \multicolumn{2}{|c|}{$t$-Test } \\
\hline & & Treatment Group & Control Group & & $t$ Value & $p$ Value \\
\hline \multirow{2}{*}{ GAP } & Before matching & 0.4171 & 0.3988 & 23.8 & 3.47 & $0.001^{* * *}$ \\
\hline & After matching & 0.4090 & 0.4003 & 7.3 & 1.45 & 0.138 \\
\hline \multirow{2}{*}{ EDU } & Before matching & 7.7850 & 7.0634 & 50.4 & 7.47 & $0.000^{* * *}$ \\
\hline & After matching & 7.4619 & 7.5045 & -5.9 & -1.57 & 0.117 \\
\hline \multirow[b]{2}{*}{ GOV } & Before matching & 0.1712 & 0.2084 & -33.3 & -5.17 & $0.000^{* * *}$ \\
\hline & After matching & 0.1787 & 0.1824 & -3.3 & -0.75 & 0.452 \\
\hline \multirow{2}{*}{$T R A$} & Before matching & 5.6374 & 5.5309 & 12.5 & 1.86 & 0.064 * \\
\hline & After matching & 5.6331 & 5.7022 & -8.1 & -1.34 & 0.182 \\
\hline \multirow{2}{*}{$M E D$} & Before matching & 10.37 & 10.219 & 28.1 & 4.03 & $0000^{* * *}$ \\
\hline & After matching & 10.26 & 10.224 & 6.8 & 1.10 & 0.271 \\
\hline
\end{tabular}

Note: ${ }^{*}$, and ${ }^{* * *}$ indicate statistical significance at $10 \%$ and $1 \%$ level, respectively.

Table 3. Result of overall balance test.

\begin{tabular}{cccccc}
\hline Matching Method & Status & Ps R $^{\mathbf{2}}$ & LR chi $^{\mathbf{2}}$ & $\boldsymbol{p}>\mathbf{c h i}^{\mathbf{2}}$ & Mean of SD (\%) \\
\hline Nearest neighbor & Before matching & 0.063 & 73.83 & 0.000 & 29.6 \\
matching & After matching & 0.005 & 5.90 & 0.316 & 6.3 \\
\hline
\end{tabular}

Table 4. Results of policy tests in central China.

\begin{tabular}{|c|c|c|c|c|c|c|c|c|c|}
\hline \multirow{2}{*}{ Variables } & \multicolumn{3}{|c|}{ Whole Central Area } & \multicolumn{3}{|c|}{ Yangtze River Economic Belt } & \multicolumn{3}{|c|}{ Non-Yangtze River Economic Belt } \\
\hline & (1) & (2) & (3) & (4) & (5) & (6) & (7) & (8) & (9) \\
\hline \multirow{2}{*}{$D I D$} & 0.0040 & 0.0083 & 0.0119 & $0.0090^{* * *}$ & $0.0061^{* * *}$ & 0.0274 & 0.0114 & 0.0129 & 0.0058 \\
\hline & $(0.0114)$ & $(0.0099)$ & $(0.0203)$ & $(0.0022)$ & $(0.0018)$ & $(0.0688)$ & $(0.0169)$ & $(0.0150)$ & $(0.0279)$ \\
\hline \multirow{2}{*}{$\ln G A P$} & & $-0.3858^{* * *}$ & $-0.4187^{* * *}$ & & $-0.4560^{* * *}$ & $-0.6071^{* * *}$ & & $-0.3983^{* * *}$ & $-0.5112^{* * *}$ \\
\hline & & $(0.0958)$ & $(0.0875)$ & & $(0.1312)$ & $(0.1029)$ & & $(0.1055)$ & $(0.0084)$ \\
\hline \multirow{2}{*}{$\ln E D U$} & & 0.0027 & 0.0064 & & 0.0040 & 0.0081 & & 0.0079 & $0.0833^{*}$ \\
\hline & & $(0.0129)$ & $(0.0339)$ & & $(0.0230)$ & $(0.0709)$ & & $(0.0166)$ & $(0.0502)$ \\
\hline \multirow{2}{*}{$\ln G O V$} & & $0.4260^{* * *}$ & $0.5805^{* * *}$ & & $0.3978^{* * *}$ & $0.4436^{* * *}$ & & $0.7725^{* * *}$ & $0.4961^{* * *}$ \\
\hline & & $(0.0964)$ & $(0.0188)$ & & $(0.1170)$ & $(0.0892)$ & & $(0.2301)$ & $(0.1897)$ \\
\hline \multirow{2}{*}{$\ln T R A$} & & $0.0271^{* * *}$ & -0.0169 & & $0.0264^{* *}$ & 0.0067 & & 0.0035 & -0.0226 \\
\hline & & $(0.0090)$ & $(0.1134)$ & & $(0.0108)$ & $(0.0091)$ & & $(0.0181)$ & $(0.0973)$ \\
\hline & & $-0.0647^{* * *}$ & -0.0172 & & -0.0564 ** & $-0.0288^{* *}$ & & $-0.1084^{* * *}$ & -0.0132 \\
\hline $\ln M E D$ & & $(0.0124)$ & $(0.0454)$ & & $(0.0272)$ & $(0.0131)$ & & $(0.0273)$ & $(0.0560)$ \\
\hline Time Effect & YES & $Y E S$ & YES & YES & $Y E S$ & $Y E S$ & YES & YES & $Y E S$ \\
\hline Area Effect & YES & YES & YES & YES & YES & YES & YES & YES & YES \\
\hline Cons & $-0.7475^{* * *}$ & $-1.7963 * * *$ & $-1.4368^{* * *}$ & $-0.7117^{* * *}$ & $-1.7038^{* * *}$ & $-2.169 * * *$ & $-0.8175^{* * *}$ & $-1.9706^{* * *}$ & $-1.5524^{* * *}$ \\
\hline Cons & $(0.0031)$ & $(0.1189)$ & $(0.0985)$ & $(0.0034)$ & $(0.1863)$ & $(0.3338)$ & $(0.0045)$ & $(0.2154)$ & $(0.0783)$ \\
\hline Observation & 783 & 783 & 783 & 519 & 519 & 519 & 264 & 264 & 264 \\
\hline
\end{tabular}

Note: ${ }^{*}, * *$ and, ${ }^{* * *}$ indicate statistical significance at the $10 \%, 5 \%$, and $1 \%$ level, respectively. Columns $1,2,4,5,7$, and 8 show estimated results using difference-in-differences (DID) method. Columns 3, 6, and 9 show estimated results using ordinary least squares (OLS) method for comparison.

In Table 4, columns 3 and 4 show the estimated results of areas in the Yangtze River Economic Belt, and columns 5 and 6 show the estimated results of areas outside the Yangtze River Economic Belt; and columns 3 and 5 show the estimated results with the addition of control variables. By analyzing the results of different regions, it can be seen that the coefficient of DID in the non-Yangtze River area is similar to the result in the overall central area (coefficient is positive and not significant). This indicates that establishing new urbanization pilot areas outside the Yangtze River Economic Belt is not significant in promoting the in situ urbanization process. However, the DID coefficients of the regressions in columns 3 and 4 in the Yangtze River Economic Belt are positive and significant at the $1 \%$ level. This indicates that establishing new urbanization pilot areas in the Yangtze River Economic Belt has a positive stimulating role on the process of in situ urbanization.

Then, we analyzed the results of the control variables. As shown in Table 4, we found that the symbols of each control variable in the regressions of columns 2, 4, and 6 are all the same. The coefficients of the rural-urban income gap (GAP) and medical level $(M E D)$ are significantly negative. The widening income gap between urban and rural areas is not conducive to the in situ employment of the rural labor force, and the 
larger income gap will make rural laborers more inclined to seek employment in cities. This is similar to Wang's research [46]. He used the instrumental variable method to conduct an empirical analysis, and believed that the widening of the urban-rural income gap hinders the process of urbanization. Regarding the medical level, most high-quality medical resources and advanced medical technology are concentrated in cities rather than in rural areas. Compared with rural areas, medical conditions have an absolute advantage in cities. This greatly attracts rural laborers to move to cities, which explains why the coefficient of medical level (MED) is significantly negative.

Our results are contrary to Cheng's views [47]. Using a random effects model, he found that an improved medical level promotes the process of urbanization. For government support $(G O V)$, the coefficient of this variable is significantly positive at $1 \%$ level. Strengthening government support in rural areas strongly improves the living conditions of rural residents and increases their income, which explains why the government's support for rural areas has played a significant role in promoting in situ urbanization. This finding is consistent with our expectations, and with many studies. For example, Ma (2014) believed that the government leads the process of urbanization and explained through a structural equation model that government support directly accelerates the speed of urbanization [48]. For traffic accessibility (TRA), this variable is also positive, but it is not significant in non-Yangtze Economic Belt areas. Compared with existing studies, our results are similar. Zhang and Liu [49,50], using double fixed-effects and generalized method of moments (GMM) models, found that less urbanized areas need better infrastructure and transportation conditions, and the convenience of transportation will accelerate the urbanization process. Finally, we found that the variable coefficient of educational resources $(E D U)$ is positive but not significant, which is not consistent with our expectation. However, Li's (2013) study, using a Solow model, found that educational resources is the main influencing factor of the urbanization process [51]. The explanation given in this paper is that this variable is expressed by higher educational resources, and there is a huge difference in the impact of higher education and primary education resources on population migration. Higher education resources have no apparent influence on most people to choose rural or urban employment. Therefore, the impact of educational resources on in situ urbanization is not significant.

\subsection{Robustness Test}

As shown in Table 4, the estimated results obtained by adding control variables have a certain reliability. In order to further test the robustness of the results in the Yangtze River Economic Belt region with significant policy effects, we referred to existing studies $[52,53]$ that conducted counterfactual tests by changing the policy implementation time. In addition to establishing new urbanization pilot areas, other policies or random factors could also lead to regional economic differences. This difference is not related to the establishment of pilot areas and ultimately leads to the failure of previous conclusions. In order to rule out the influence of these factors, we assumed that each region would set up new urbanization pilot areas two or three years in advance. If the policy variable coefficient $\theta$ is still significantly positive, then the promoting role of in situ urbanization is likely to come from other random factors or policies, rather than the establishment of pilot areas. If $\theta$ is not significant at this time, it indicates that improving in situ urbanization is affected by the establishment of new pilot areas. In Table 5, the results in columns 1 and 2 show that the time for establishing a new pilot area is assumed to be two years in advance. The results shown in columns 3 and 4 suggest that the time is assumed to be three years in advance. From the estimated results of columns 1-4, it can be seen that whether the policy is implemented two or three years in advance, the values of coefficient $\theta$ are not significant. This reveals that for the cities in the Yangtze River Economic Belt, the improved level of in situ urbanization is not caused by other factors but is promoted by the establishment of pilot areas. 
Table 5. Results of robustness test.

\begin{tabular}{|c|c|c|c|c|c|c|}
\hline \multirow{2}{*}{ Variables } & \multicolumn{4}{|c|}{ Counterfactual Test } & \multicolumn{2}{|c|}{ Single Difference Test } \\
\hline & (1) & (2) & (3) & (4) & (5) & (6) \\
\hline L2_DID & $\begin{array}{c}0.0045 \\
(0.0101)\end{array}$ & $\begin{array}{c}0.0162 \\
(0.0138)\end{array}$ & & & & \\
\hline L3_DID & & & $\begin{array}{c}0.0126 \\
(0.0094)\end{array}$ & $\begin{array}{c}0.0227 \\
(0.0153)\end{array}$ & & \\
\hline DID & & & & & $\begin{array}{c}0.0470 * * * \\
(0.0091)\end{array}$ & $\begin{array}{c}0.0206^{* * *} \\
(0.0048)\end{array}$ \\
\hline $\ln G A P$ & & $\begin{array}{c}-0.5266^{* * *} \\
(0.1128)\end{array}$ & & $\begin{array}{c}-0.4649^{* * *} \\
(0.1049)\end{array}$ & & $\begin{aligned}- & 0.4153^{* * *} \\
& (0.1299)\end{aligned}$ \\
\hline $\ln E D U$ & & $\begin{array}{c}0.0072 \\
(0.0192)\end{array}$ & & $\begin{array}{c}0.0086 \\
(0.0191)\end{array}$ & & $\begin{array}{c}0.0041 \\
(0.0228)\end{array}$ \\
\hline $\ln G O V$ & & $\begin{array}{c}0.4056^{* * *} \\
(0.1110)\end{array}$ & & $\begin{array}{c}0.4511^{* * *} \\
(0.1139)\end{array}$ & & $\begin{array}{c}0.3583^{* * * *} \\
(0.1207)\end{array}$ \\
\hline $\ln T R A$ & & $\begin{array}{l}0.0253^{* *} \\
(0.0109)\end{array}$ & & $\begin{array}{c}0.0301^{* * * *} \\
(0.0110)\end{array}$ & & $\begin{array}{c}0.0265 \\
(0.0184)\end{array}$ \\
\hline $\ln M E D$ & & $\begin{array}{c}-0.0644^{* * *} \\
(0.0153)\end{array}$ & & $\begin{array}{c}-0.0759^{* * *} \\
(0.0167)\end{array}$ & & $\begin{array}{c}-0.0515^{*} \\
(0.0271)\end{array}$ \\
\hline Time Effect & YES & YES & YES & YES & NO & NO \\
\hline Area Effect & YES & YES & YES & YES & YES & YES \\
\hline Cons & $\begin{array}{c}-0.7273^{* * *} \\
(0.0045)\end{array}$ & $\begin{array}{c}-1.8253^{* * *} \\
(0.1702)\end{array}$ & $\begin{array}{c}-0.7354 \text { *** } \\
(0.0049)\end{array}$ & $\begin{array}{c}-1.9551^{* * *} \\
(0.1890)\end{array}$ & $\begin{array}{c}-0.7065^{* * *} \\
(0.0038)\end{array}$ & $\begin{array}{c}-1.6345^{* * *} \\
(0.1796)\end{array}$ \\
\hline Observation & 519 & 519 & 519 & 519 & 519 & 519 \\
\hline
\end{tabular}

Note: ${ }^{*}$, and ${ }^{* * *}$ indicate statistical significance at the $10 \%$ and $1 \%$ level, respectively.

Besides constructing a counterfactual test to enhance the robustness of the results, we also adopted the single difference to test the policy effect by controlling only the regional effect but not the time effect. The estimated results are shown in Table 5, columns 5 and 6 . After controlling other variables and regional effects, the estimated coefficients of the policy variable (DID) are positive and significant at $1 \%$, which also indicates that establishing new urbanization pilot areas in the Yangtze River Economic Belt has a certain promoting effect on in situ urbanization. However, through further analysis, we found that the coefficient of the policy variable estimated by the single difference method is significantly larger than the difference-in-differences method in Table 3, which means that the results estimated by the former overestimate the policy effect. Therefore, we believe that the conclusion obtained by using the difference-in-differences method has certain credibility.

\section{Conclusions, Limitations, and Implications}

\subsection{Conclusions and Limitations}

Taking the panel data of 87 prefecture-level cities in central China from 2009 to 2018 as samples, this paper tested the impact of establishing new urbanization pilot areas on in situ urbanization through the time-varying difference-in-differences model, and enhanced the robustness of the estimated results with the counterfactual and single difference tests. The following conclusions were drawn from the above studies:

(1) In the central region, the establishment of new urbanization pilot areas has not played a significant role in promoting the process of in situ urbanization. By dividing the central cities into the Yangtze River and non-Yangtze River Economic Belt areas, we also find that the effect of the new urbanization policy is not obvious for cities outside the Economic Belt. (2) The central cities located in the Yangtze River Economic Belt have significant policy effects due to their advantages in transportation, resources, industry, labor, etc. The establishment of new urbanization pilot areas has a significant promoting effect on the process of in situ urbanization. (3) Control variables such as urban-rural income gap, medical level, government support, and traffic accessibility have different influences on local urbanization, among which the first two hinder the process and the second two have a positive effect on the process of in situ urbanization. 
The main limitation of this research is the time limitation of the new urbanization policy. This policy was implemented from 2014 to 2020. It is impossible to analyze its impact on in situ urbanization after 2020. We do not know whether this policy has a lagging effect on the process after 2020. In addition, another limitation is that there may have been omissions or unknown factors in the selection of control variables. In the next step, we will analyze the level of in situ urbanization in the eastern and western regions and study its development mechanism from an industry-led perspective. Then we will look for in situ urbanization development models that suit different regions of our country, which will effectively improve some existing problems in the current stage.

\subsection{Implications}

Based on the above analysis and conclusions, we offer some suggestions:

(1) Promote rural industrialization and expand employment channels.

The development of in situ urbanization should be based on employment and industry, combining residential construction, land use, and industrial development. The goal of residential construction is to solve the problem of wasted land resources and public infrastructure caused by the scattered settlement in traditional villages. Residential construction in the process of in situ urbanization should improve infrastructure, community planning, and housing construction, to help farmers enjoy a life with a good ecological environment and complete infrastructure. The industrialization of agriculture is conducive to the connection between scattered small-scale and socialized large-scale production. The key to agricultural industrialization is to be market-oriented, use advanced science and technology, develop characteristic industries, and optimize rural production factors, which can realize mechanization and specialization in agricultural production. In addition, it is necessary to give full play to the supporting role of industrial development for in situ urbanization. Actions such as accelerating industrial agglomeration, combining local resource characteristics, and rationally determining industrial layouts will also provide farmers with more employment opportunities.

(2) Promote institutional reform to ensure sustainable in situ urbanization.

From the perspective of rural economic development, the urban-rural dual structure has become a constraint to the current development of in situ urbanization. Therefore, it is necessary to reform the existing household registration, land, and social security systems to provide an institutional guarantee for the sustainable and healthy development of in situ urbanization. In the dual household registration system, there are many inequalities between rural and urban residents, so it is necessary to register residents in a unified way that reflects the principles of fairness and justice. Regarding the reform of the land system, local governments should accelerate the confirmation of land ownership and actively explore new forms of land circulation. Greater coverage of the social security system and equal infrastructure construction and services between urban and rural areas will create a healthy and sustainable environment for in situ urbanization.

(3) Build a beautiful countryside and create a livable environment.

Against the background of "Beautiful China," the difference between in situ and traditional urbanization is that the former can create a better ecological environment and focuses on the balanced development of economic and ecological benefits. The construction of a beautiful countryside is an important way to realize agricultural modernization and in situ urbanization. The construction of a beautiful countryside should be accomplished in three aspects. First is to protect the ecological environment and explore the natural beauty. In the process of community construction, attention should be paid to protecting the original rural ecological environment and organically integrating pastoral scenery and rural charm. Second, we should create a good living environment through reasonable design and layout. Narrowing the urban-rural gap of infrastructure and public services and strengthening the management of new communities are significant initiatives. Third is to pay attention to the construction of cultural towns. In addition to creating a good 
natural environment, we should pay attention to enriching farmers' spiritual lives and improving their cultural and moral quality.

All in all, the traditional urbanization model can no longer meet the needs of current urbanization development. Against the background of rural economic development, the advantages of in situ urbanization, as the main approach and development trend of new urbanization, are gradually highlighted. In view of the current situation, the time is not yet ripe for comprehensively promoting in situ urbanization; we must overcome difficulties and remove multiple obstacles in the process. The construction of in situ urbanization is a systematic project that needs a scientific and reasonable layout, emancipation of peasants ${ }^{\prime}$ ideology, and reform of unreasonable systems.

Author Contributions: Funding acquisition, X.H.; Investigation, Q.W.; Supervision, G.T.; Writingoriginal draft, Y.L.; Writing—review and editing, J.P. and Q.W. All authors have read and agreed to the published version of the manuscript.

Funding: This research received no external funding.

Institutional Review Board Statement: Not applicable.

Informed Consent Statement: Not applicable.

Acknowledgments: This work was supported by the Chinese Academy of Social Sciences Foundation Project (2015YZD6), and the Nanchang University Graduate Innovation Fund Project (CX2018003).

Conflicts of Interest: The authors declare no conflict of interest.

\section{References}

1. Henderson, V. The urbanization process and economic growth: The so-what question. J. Econ. Growth 2003, 8, 47-71. [CrossRef]

2. Wang, Q.; Su, M. The effects of urbanization and industrialization on decoupling economic growth from carbon emission-A case study of China. Sustain. Cities Soc. 2019, 51, 101758. [CrossRef]

3. Available online: http://www.gov.cn/zhengce/2014-03/16/content_2640075.htm (accessed on 9 October 2020).

4. Tang, S.; Hao, P.; Huang, X. Land conversion and urban settlement intentions of the rural population in China: A case study of suburban Nanjing. Habitat Int. 2016, 51, 149-158. [CrossRef]

5. Li, Y.; Jia, L.; Wu, W.; Yan, J.; Liu, Y. Urbanization for rural sustainability-Rethinking China's urbanization strategy. J. Clean. Prod. 2018, 178, 580-586. [CrossRef]

6. Ahlers, A.L. Weaving the Chinese dream on the ground? Local government approaches to "new-typed" rural urbanization. J. Chin. Political Sci. 2015, 20, 121-142. [CrossRef]

7. Wang, X.R.; Hui, E.C.M.; Choguill, C.; Jia, S.H. The new urbanization policy in China: Which way forward. Habitat Int. 2015, 47, 279-284. [CrossRef]

8. Su, L.; Fan, J.; Fu, L. Exploration of smart city construction under new urbanization: A case study of Jinzhou-Huludao Coastal Area. Sustain. Comput. Inform. Syst 2020, 27, 100403. [CrossRef]

9. Chen, M.; Liu, W.; Lu, D. Challenges and the way forward in China's new-type urbanization. Land Use Policy 2016, 55, 334-339. [CrossRef]

10. Liang, W.; Yang, M. Urbanization, economic growth and environmental pollution: Evidence from China. Sustain. Comput. Inform. Syst. 2019, 21, 1-9. [CrossRef]

11. Chen, C.; LeGates, R.; Zhao, M.; Fang, C. The changing rural-urban divide in China's megacities. Cities 2018, 81, 81-90. [CrossRef]

12. Liu, Y. Introduction to land use and rural sustainability in China. Land Use Policy 2018, 74, 1-4. [CrossRef]

13. Zhang, P.; Yuan, H.; Tian, X. Sustainable development in China: Trends, patterns, and determinants of the "Five Modernizations" in Chinese cities. J. Clean. Prod. 2019, 214, 685-695. [CrossRef]

14. Tan, Y.; Xu, H.; Zhang, X. Sustainable urbanization in China: A comprehensive literature review. Cities 2016, 55, 82-93. [CrossRef]

15. Zhou, T.; Jiang, G.; Zhang, R.; Zheng, Q.; Ma, W.; Zhao, Q.; Li, Y. Addressing the rural in situ urbanization (RISU) in the Beijing-Tianjin-Hebei region: Spatio-temporal pattern and driving mechanism. Cities 2018, 75, 59-71. [CrossRef]

16. Zhu, Y. New Paths to Urbanization in China: Seeking More Balanced Patterns; Nova Publishers: Harpark, NY, USA, 1999.

17. Zhu, Y. In situ urbanization in rural China: Case studies from Fujian Province. Dev. Change 2000, 31, 413-434. [CrossRef]

18. Cui, S.P.; Zhao, Q.Y. The Inspiring and Thinking for In-Situ Urbanization of South Jiangsu. Urban Dev. Stud. 2013, $20,47-51$.

19. Chan, X.; Bin, L.; Tianzuo, W. New Patterns of County In-Situ Urbanization and Rural Development Based on E-Commerce. Urban Plan. Int. 2015, 1, 14-21.

20. Liu, S.; Zhang, P.; Lo, K. Urbanization in remote areas: A case study of the Heilongjiang Reclamation Area, Northeast China. Habitat Int. 2014, 42, 103-110. [CrossRef]

21. Zhu, Y. In situ urbanization in China: Processes, contributing factors, and policy implications. China Popul. Dev. Stud. 2017, 1, 45-66. [CrossRef] 
22. Qi, X.; Zhu, Y.; Zhou, Y.P. Adouble-pull model of rural labor migration and its in situ urbanizationeffect: Cases studies of three coastal areas in southeast China. Sci. Geogr. Sin. 2012, 32, 25-30.

23. Guo, S.; Zou, J. Study and Enlightenment of the In-Situ Urbanization of Rural Areas in China in the Background of New Pattern Urbanization-Taking Zhanqi Village, Pi County for Instance. Open J. Soc. Sci. 2015, 3, 137. [CrossRef]

24. Deng, X.; Huang, J.; Rozelle, S.; Zhang, J.; Li, Z. Impact of urbanization on cultivated land changes in China. Land Use Policy 2015, 45, 1-7. [CrossRef]

25. Qian, H.; Wong, C. Master planning under urban-rural integration: The case of Nanjing, China. Urban Policy Res. 2012, 30, 403-421. [CrossRef]

26. Lang, W.; Chen, T.; Li, X. A new style of urbanization in China: Transformation of urban rural communities. Habitat Int. 2016, 55, 1-9. [CrossRef]

27. Ma, L.; Chen, M.; Che, X.; Fang, F. Farmers' Rural-To-Urban Migration, Influencing Factors and Development Framework: A Case Study of Sihe Village of Gansu, China. Int. J. Environ. Res. Public Health 2019, 16, 877. [CrossRef] [PubMed]

28. Meng, L.; Zhao, M.Q.; Liwu, D.S. Joint migration decisions of married couples in rural China. China Econ. Rev. 2016, 38, 285-305. [CrossRef]

29. Qin, H.; Liao, T.F. Labor out-migration and agricultural change in rural China: A systematic review and meta-analysis. J. Rural. Stud. 2016, 47, 533-541. [CrossRef]

30. Qiang, L. An analysis of push and pull factors in the migration of rural workers in china. Soc. Sci. China 2003, 1, 125-136.

31. Chen, H.; Wang, X. Exploring the relationship between rural village characteristics and Chinese return migrants' participation in farming: Path dependence in rural employment. Cities 2019, 88, 136-143. [CrossRef]

32. Zhang, Z.; Wen, Y.; Wang, R.; Han, W. Factors influencing rural households' willingness of centralized residence: Comparing pure and nonpure farming areas in China. Habitat Int. 2018, 73, 25-33. [CrossRef]

33. Pan, Y.; Pan, Y.; Cai, Y. Research on the Path of In-situ Urbanization and the Sustainable Development-A Case Study of You Yang County in Chongqing. China Popul. Resour. Environ. 2016, S1, 549-552.

34. Xu, C.; Wang, S.; Zhou, Y.; Wang, L.; Liu, W. A comprehensive quantitative evaluation of new sustainable urbanization level in 20 Chinese urban agglomerations. Sustainability 2016, 8, 91. [CrossRef]

35. Chu, Y.W. China's new urbanization plan: Progress and structural constraints. Cities 2020, 103, 102736. [CrossRef]

36. Jin, W.; Zhou, C.; Zhang, G. Characteristics of state-owned construction land supply in Chinese cities by development stage and industry. Land Use Policy 2020, 96, 104630. [CrossRef]

37. Yi-Bo, Y. The Coupling Analysis of Agricultural Surplus Labor Transfer and New Urbanization Construction. Sci. Econ. Soc. 2020, $38,57-62$.

38. Tan, M. Uneven growth of urban clusters in megaregions and its policy implications for new urbanization in China. Land Use Policy 2017, 66, 72-79. [CrossRef]

39. Ashenfelter, O.; Card, D. Using the longitudinal structure of earnings to estimate the effect of training programs. Natl. Bur. Econ. Res. 1984. [CrossRef]

40. Yang, J.; Huang, X.; Liu, X. An analysis of education inequality in China. Int. J. Educ. Dev. 2014, 37, 2-10. [CrossRef]

41. Bureau, C.S. China Statistical Yearbook; China Statistical Bureau: Beijing, China, 2016.

42. Cheng, C. China's Economic Development: Growth and Structural Change; Routledge: London, UK, 2019.

43. The State Council Issue the 13th Five-Year Plan for the Development of Modern Comprehensive Transport System. Available online: http:/ / www.gov.cn/zhengce/content/2017-02/28/content_5171345.htm (accessed on 4 May 2020).

44. Ranking of the Urbanization Rate of Permanent Resident Population of All Provinces and Cities in 2019. Available online: https:/ / s.askci.com/news/hongguan/20200422/1346571159528.shtml (accessed on 4 May 2020).

45. Heckman, J.J.; Ichimura, H.; Todd, P.E. Matching as an econometric evaluation estimator: Evidence from evaluating a job training programme. Rev. Econ. Stud. 1997, 64, 605-654. [CrossRef]

46. Wang, C.; Ma, W. Relations of Balanced Development of Urban-Rural Education and Urban-Rural Income Gap with the New Urbanization. Financ. Econ. 2014, 8, 97-108.

47. Cheng, M.; Yang, M. Impact of Urbanization on the Health of Chinese Residents: An Empirical Study Based on Provincial Panel Data. China Popul. Resour. Environ. 2015, 7, 89-96.

48. Ma, X. Analysis on the Key Influence Factors of Urbanization and Its Effects in China. China Popul. Resour. Environ. 2014, 12, 117-124.

49. Zhang, G.; Chen, G. Research on Determinants of Infrastructure Investment: Based on Analysis of a Multinational Panel Data. J. World Econ. 2009, 3, 34-44.

50. Liu, S.; Hu, A. Test on the Externality of Infrastructure in China: 1988-2007. Econ. Res. J. 2010, 3, 4-15.

51. Li, D.; Xia, E. Research on the Influence of Human Capital on China Economy Growth Based on Extended Solow Model. China. Popul. Resour. Environ. 2013, 23, 100-106.

52. Ziying, F.; Binbin, T. Tax competition, Tax enforcement and tax avoidance. Econ. Res. J. 2013, 9, 99-111.

53. Pesaran, M.H.; Smith, R.P. Counterfactual analysis in macroeconometrics: An empirical investigation into the effects of quantitative easing. Res. Econ. 2016, 70, 262-280. [CrossRef] 